\title{
A generalized Reed model with application to wildfire risk in even-aged Southern United
}

\section{States pine plantations}

\author{
Andres Susaeta ${ }^{\mathrm{a}^{*}}$, Douglas R. Carter ${ }^{\mathrm{b}}$, Sun Joseph Chang ${ }^{\mathrm{c}}$, and Damian C. Adams ${ }^{\mathrm{d}}$
}

a315 Newins Ziegler Hall, School of Forest Resources and Conservation, University of Florida,

P.O. Box 110410, Gainesville, Florida, 32611, USA. Email: asusaeta@ufl.edu, phone: 1-352-

846-0877; fax: 1-352-8461277. "Corresponding author.

${ }^{\mathrm{b}} 357$ Newins Ziegler Hall, School of Forest Resources and Conservation, University of Florida, Gainesville, Florida, USA. Email: drcart@ufl.edu.

c319 Renewable Natural Resources Building, School of Renewable Resources, Louisiana State University, Baton Rouge, Louisiana, USA. Email: xp2610@1su.edu.

${ }^{d} 355$ Newins Ziegler Hall, School of Forest Resources and Conservation, University of Florida, Gainesville, Florida, USA. Email: dcadams@ufl.edu. 


\title{
A generalized Reed model with application to wildfire risk in even-aged Southern United States pine plantations
}

\begin{abstract}
We develop a generalized Reed model to incorporate the risk of wildfires on optimal management of slash pine (Pinus elliotti var. elliotti) in the southern United States. Comparative static analyses are conducted to determine the impacts of the probability of increasing and constant wildfire risk as forest stand ages, and portion of stand that is salvageable following a wildfire, on slash pine harvest decisions. Our results reveal that increasing the current risk of wildfire damage would shorten the current optimal slash pine harvest age, while increasing the future risk of wildfire losses would lengthen the current optimal harvest age. We also compare the impacts of different wildfire arrival paths (rising and constant arrival rate with stand age) on the optimal forest management of slash pine. Under the generalized model, increases in future rising wildfire risks have less impact than increases in future constant wildfire risks on the optimal harvest ages for the current crop. Increases in the current rising risk of wildfires have a similar impact on the optimal harvest age compared to increases in the current constant risk of wildfires.

Keywords: harvest age; land expectation value; non-homogenous Poisson process; Reed model; wildfires
\end{abstract}




\section{Introduction}

The Faustmann model, published in 1849 (1995), describes the forest owner's problem of selecting the rotation age that maximizes the net present value of forest-related cash flows. A major limitation of the model is its deterministic nature. Risks related to natural hazards such as hurricanes, wildfires, flooding, pest outbreaks, ice storms and droughts influence forest management decision making (Amacher et al., 2009); yet the classic Faustmann model fails to incorporate these risks.

Reed (1984) adapted the Faustmann model to explicitly incorporate risk from natural hazards. His model assesses the effect of catastrophic event risk on optimal timber harvesting and profitability of a forest stand embedded within a Faustmann framework. This approach has been widely used to determine optimal forest management, mainly for risk of fire (Reed, 1984; Reed and Errico, 1985; Susaeta et al., 2009). Englin et al. (2000) included amenity values subject to the risk of fire. Stainback and Alavalapati (2002) adapted the Reed model to incorporate payments for carbon sequestration. Amacher et al. (2005) extended the Reed model by incorporating fuel reduction decisions and modeling timber salvage as a function of stand density and fuel reduction treatments to protect forest landowners against losses.

One of the limitations of the traditional Reed model is that real stumpage prices, stand volume and real regeneration costs are assumed to be constant for all harvest time periods. Instead, these parameters are likely to vary between timber crops ${ }^{1}$, thus the harvesting decision is also

\footnotetext{
${ }^{1}$ For example, forest stumpage prices are widely acknowledged to vary as timber crop ages due to different mixes of forest products. Forest growth and thus stand volume are influenced by silvicultural treatments and external factors such as climate and risk events which are likely to vary
} 
expected to change over successive timber crops. Two salient parameters of the Reed model are the probability of a catastrophic risk event and the salvageable portion of the damaged timber crop. Both parameters are also likely to change over successive timber crops. Age, biological, and ecological conditions of the forest stand may also influence the probability of a natural hazard (Amacher et al., 2009; Reed, 1984) and the possibility of salvage operations (Amacher et al., 2005; Amacher et al., 2009). For example, older timber stands that have accumulated flammable woody material would be more prone to wildfires (Li et al., 1997). Temperatures are expected to rise over time due to climate change, and with that come a whole host of expected climate related impacts, including increased risk of hurricanes, wildfires, and pests. Climate change would likely result in more intensive future storms in general (Karl et al., 2009). The probability of wildfires and invasive species may increase after a hurricane (Myers and Van Lear, 1998). Current and future macroeconomic conditions and reduction in fuel loads would also influence timber salvage operations. Increased salvage logging would be expected as higher returns are realized (Prestemon and Holmes, 2008). Salvage logging intensity might also decline if it negatively affected the forest stand structure, ecosystem process, and community composition (Lindenmayer and Noss, 2006).

We present, unlike previous studies, a generalized version of the Reed model that accounts for not only risk of natural hazards but also allows all other factors to vary between different timber crops. The novelty of this generalized model- as opposed to the traditional Reed model-lays in

over successive rotations. For example, loss in productivity of the forest stand after several rotations is associated with intensive site and harvesting operations (Evans, 2009). Further, the development of new technologies (Saarinen, 2006) or changes in tree density over successive rotations may alter forest regeneration costs. 
the capacity to incorporate the impact of risk of future natural hazards, and future salvage possibilities on the current landowners' harvesting decision, within the context of wildfire events ${ }^{2}$.

The dynamic nature of future natural hazards given expected changing climatic conditions is an essential component of the complex decision-making process for forest landowners (Yousefpour et al., 2012). With higher expected fire activity in the South's spring season over the $21^{\text {st }}$ century, due to global warming conditions (Bedel et al., 2013), the future investment in forestry and current optimal forest management will be undoubtedly impacted. Our model allows for the analytical estimation of profitability of forestlands and current harvesting decision from wildfire events expected to affect current and future timber crops. Given the influence that wildfire events have on forest management decisions, and concerns that climate change may exacerbate risks related to this natural disturbance, the flexibility of our stand-level model would permit closer examination of event impacts on forestry decision making.

This paper is organized as follows: first, we outline the underlying features of the traditional Reed model and followed up with the development of the generalized Reed model. Next, using the generalized model, we ascertain the effects of catastrophic current and future risks on the optimal harvest age for the current stand. We then discuss the historical effect of wildfires on southern U.S. forestlands and apply the model to a representative southern pine species-slash pine

\footnotetext{
${ }^{2}$ Wildfires represent a major economic threat in the U.S. Wildfire suppression expenditures by the United States Forest Services totaled, on average, $\$ 1.2$ billion annually between 2001 and 2010 (Stein et al., 2013). Total costs of six weeks of large wildfires in Florida accounted for \$522 million to $\$ 762$ million in 1998 (Stein et al., 2013).
} 
(Pinus elliotti var. elliotti)-and discuss the results. We also contrast the impacts of different wildfire arrival paths on the optimal forest management of slash pine. Finally, we offer some concluding remarks and recommendations for further research.

\section{Derivation of the generalized Reed model}

\subsection{The traditional Reed model}

Reed's classic economic model (Reed, 1984) incorporated the effect of risk of a catastrophic event and salvageable portion of the forest into the Faustmann model. Reed (1984) assumed that the catastrophic event followed a non-homogenous Poison process, with and distribution parameter $\lambda$ dependant on forest stand age ${ }^{3}, \lambda=\lambda(X)$. The $\lambda$ parameter represented the probability of occurrence of a fire in any given year. We also assumed a rising rate of damaging fire arrival as forest stand ages, i.e., $\lambda^{\prime}(X)>0$. It is further assumed that the time between successive fires events-the age of the stand at the time when fires occurs-was a random variable $X$ that followed an exponential distribution with cumulative density function $1-e^{-m(X)}$, where $m(X)=\int_{0}^{X} \lambda(q) d q$ and is increasing in $X$, thus $\frac{d m}{d X}=\lambda(X)$. The probability that a fire event may affect a forest stand before reaching the economically optimal rotation age $T$ was $\operatorname{Pr}(X<T)=$ $1-e^{-\mathrm{mT}}$ and the probability of the stand reaching the optimal rotation without being affected by

\footnotetext{
${ }^{3}$ Reed (1984) also assumed that fire risk follows a homogenous Poisson distribution, i.e., the fire arrival is not dependant on the forest stand age. Other studies such as Stainback and Alavalapati (2004) and Susaeta et al. (2009) also considered that the disturbance risk does not vary with the age of the trees.
} 
a fire event was $\operatorname{Pr}(X=T)=e^{-\mathrm{m} T}$. The probability density function of $X$ before reaching the optimal rotation age $(0<X<T)$ is given by $\lambda(X) e^{-\mathrm{m} X}$.

Thus, the net revenues for a forest landowner would depend on two states of the world. In the first state of the world, a catastrophic event (i.e., wildfires) arrives at time $t$ before the stand could reach the optimal rotation age $T$. Following the event, the landowner salvages a random proportion $g(t)$ of the forest with mean $\bar{g}(t)$ and incurs the regeneration costs $(C)$ associated with the new forest stand. In the second state of the world, the landowner receives the net returns from harvesting the forest stand at the optimal rotation age without being affected by a wildfire, and incurs the replanting costs $(C)$ for a new forest stand. Assuming that the time between successive stand harvest and/or destruction is $X_{n}$ for $n$ rotations, and $P$ and $Q(T)$ represent the stumpage price, and volume of the stand at time $T$, respectively, we obtain the following net economic revenues $Y_{n}$ for the first rotation:

$$
Y_{n}=\left\{\begin{array}{cc}
\bar{g}\left(X_{n}\right) P Q\left(X_{n}\right)-C & \text { if } X_{n}<T \\
P Q(T)-C & \text { if } X_{n}=T
\end{array}\right.
$$

Following Reed (1984) it is assumed that a landowner will have to harvest the stand at the optimal rotation age and replant to start a new rotation, or salvage a proportion of the stand in face of a catastrophic event and replant. This process continues ad infinitum. Thus, the sum of net present economic returns due to either harvesting or salvaging undamaged timber of equal successive rotations in perpetuity (land expectation value $L E V$ ) is as follows:

$$
L E V(T)=\frac{E\left(e^{-r X_{Y}}\right)}{1-E\left(e^{-r X}\right)}=\frac{[P Q(T)-C] e^{-(r T+\mathrm{m}(\mathrm{T}))}+\int_{0}^{T} \lambda(\mathrm{X})\left[\bar{g}\left(X_{n}\right) P Q\left(X_{n}\right)-C\right] e^{-(r X+m(X))} d X}{\frac{r e^{-(r T+m(T))}}{\lambda(\mathrm{T})+\mathrm{r}}}
$$


Where $\mathrm{r}$ is the real discount rate. The time $T$ that maximizes the LEV is the optimal rotation age. The full derivation of this model can be found in Reed (1984).

\subsection{The generalized Reed model}

To derive a generalized Reed formula, we follow similar assumptions developed by Reed (1984) with the caveat that, as evidenced in the introduction section, the parameters are unlikely to be the same from harvest to harvest. For each timber crop, a landowner will have to replant a new timber crop regardless of the event (stand harvest or salvage due to fire arrival), facing different levels of stumpage prices and forest growth, regeneration costs, discount rates, wildfire risk, and salvageable portions. Thus, the optimal harvest age is also expected to fluctuate from timber crop to timber crop. For simplicity's sake we assume that regeneration costs, and real discount rate to vary from timber crop to timber crop but independently of the age of the trees.

We assume that fluctuations of stumpage prices and volume of the forest stand from timber crop to timber crop also depend on the age of the forest $\operatorname{stand}^{4}$. In the case of the salvageable portion, it has been considered difficult to model (Reed and Errico, 1985). Amacher, et al. (2005) have modeled it as an increasing and decreasing function, respectively, of intermediate treatments and tree density. In our particular case and following Reed and Errico (1985), we assume a mean value of the salvageable portion to vary between each timber crop. In the case of a fire event, the

\footnotetext{
${ }^{4}$ As the forest stand ages different proportions of forest products are obtained with different prices. We have not considered changes in stumpage prices over the rate of inflation in our analysis. For stochastic stumpage prices (real option theory) see Gjolberg and Guttormsen (2002), and Insley and Rollins (2005).
} 
probability of arrival is likely to depend on the age of the forest stand (Amacher et al., 2005). It is expected that the ignition of a forest stand increases as forest stand ages due to the accumulation of flammable materials over time such as dead wood, branches and debris. The fire arrival is also dependent on climate factors (Stanturf and Goodrick, 2013). Increased temperatures and periods of droughts and changes in precipitation patterns may increase the frequency and length of the wildfire season (Stein et al., 2013). We note, however, that our model does not directly account for the wildfire intensity but the probability of arrival of wildfires. We know that high-intensity wildfires result in high rates of tree mortality (Outcalt and Wade, 2004). Our model assumes that salvaging the damaged trees found in the forest stand is not possible, and only the undamaged trees are available for salvage logging (Amacher et al., 2009). As a result, our model indirectly assumes that wildfire intensity is reflected by the occurrence and extent of salvage logging, and that a higher proportion of timber can be salvaged after a low intensity wildfire and vice versa.

We extend the notation for the parameters employed in Eqs. (1) and (2) to reflect a particular timber crop. The parameters of the generalized Reed model are defined in Table 1. Illustratively, the expected net present value of harvesting at the optimal harvest age or salvaging a portion of the trees for the first and second timber crop, are, respectively:

$$
\begin{aligned}
& E\left(e^{-r_{1} X_{1}} Y_{1}\right)=-C_{0}+\left[P_{1}\left(T_{1}\right) Q_{1}\left(T_{1}\right)-C_{1}\right] e^{-\left(r_{1} T_{1}+m_{1}\left(T_{1}\right)\right)}+ \\
& \left.\int_{0}^{T_{1}} \lambda_{1}\left(X_{1}\right)\left[\bar{g}_{1}\left(X_{1}\right) P_{1}\left(X_{1}\right) Q_{1}\left(X_{1}\right)-C_{1}\right)\right] e^{-\left(r_{1} X_{1+} m_{1}\left(X_{1}\right)\right)} d X_{1} \\
& E\left(e^{-\left(r_{1} X_{1}+r_{2} X_{2}\right)} Y_{2}\right)=\left\{\left[P_{2}\left(T_{2}\right) Q_{2}\left(T_{2}\right)-C_{2}\right] e^{-\left(r_{2} T_{2}+m_{2}\left(T_{2}\right)\right)}+\right. \\
& \int_{0}^{T_{2}} \lambda_{2}\left(X_{2}\right)\left[\bar{g}_{2}\left(X_{2}\right) P_{2}\left(X_{2}\right) Q_{2}\left(X_{2}\right)-\right. \\
& \left.\left.C_{2}\right] e^{-\left(r_{2} X_{2+} m_{2}\left(X_{2}\right)\right)} d X_{2}\right\} e^{-\left(r_{1} T_{1+} m_{1}\left(T_{1}\right)\right)}
\end{aligned}
$$

Place Table 1 approximately here 
For the first timber crop (Eq. (3)), a landowner will realize total net economic returns given by the sum of two states of the world: in the absence of a fire, he will receive an income of $P_{1}\left(t_{1}\right) Q_{1}\left(t_{1}\right)$ at the moment of harvesting and incur the replanting $\cos t C_{1}$ for the following timber crop (first state of the world). Under the presence of a fire event before the optimal harvest age, he will realize the net economic revenues due to salvage $\left.\int_{0}^{T_{1}} \lambda_{1}\left(X_{1}\right)\left[\bar{g}_{1}\left(X_{1}\right) P_{1}\left(X_{1}\right) Q_{1}\left(X_{1}\right)-C_{1}\right)\right] e^{-\left(r_{1} X_{1+} m_{1}\left(X_{1}\right)\right)} d X_{1}$ (second state of the world) and start a new timber crop. The net economic returns of the second timber crop (Eq. (4)) are thus the sum of $\quad P_{2}\left(T_{2}\right) Q_{2}\left(T_{2}\right)-C_{2} \quad$ (absence $\quad$ of $\quad$ fire $\quad$ event) plus $\int_{0}^{T_{2}} \lambda_{2}\left(X_{2}\right)\left[\bar{g}_{2}\left(X_{2}\right) P_{2}\left(X_{2}\right) Q_{2}\left(X_{2}\right)-C_{2}\right] e^{-\left(r_{2} X_{2+} m_{2}\left(X_{2}\right)\right)} d X_{2}$ (presence of a fire event). All future net economic rents are discounted accordingly to obtain the expected net present values for each timber crop. It becomes obvious that the same treatment described above applies for successive timber crops. Under the generalized Reed model (GRM), by defining $L E V_{i}$ as the land expectation value at the beginning of the $i$ th timber crop, the land expectation value at the beginning of the first timber crop $L E V_{1}$ is formulated as follows:

$$
\begin{aligned}
L E V_{1}= & -C_{0}+\left\{P_{1}\left(T_{1}\right) Q_{1}\left(T_{1}\right)-C_{1}+e^{\left(r_{1} T_{1+} m_{1}\left(T_{1}\right)\right)} \int_{0}^{T_{1}} \lambda_{1}\left(X_{1}\right)\left[\bar{g}_{1}\left(X_{1}\right) P_{1}\left(X_{1}\right) Q_{1}\left(X_{1}\right)-\right.\right. \\
& \left.\left.C_{1}\right] e^{-\left(r_{1} X_{1+} m_{1}\left(X_{1}\right)\right)} d X_{1}\right\} e^{-\left(r_{1} T_{1+} m_{1}\left(T_{1}\right)\right)}+\left\{P_{2}\left(T_{2}\right) Q_{2}\left(T_{2}\right)-C_{2}+\right. \\
& e^{\left(r_{2} T_{2+} m_{2}\left(T_{2}\right)\right)} \int_{0}^{T_{2}} \lambda_{2}\left(X_{2}\right)\left[\bar{g}_{2}\left(X_{2}\right) P_{2}\left(X_{2}\right) Q_{2}\left(X_{2}\right)-\right. \\
& \left.\left.C_{2}\right] e^{-\left(r_{2} X_{2+} m_{2}\left(X_{2}\right)\right)} d X_{2}\right\} e^{-\left(r_{1} T_{1+} m_{1}\left(T_{1}\right)\right)} e^{-\left(r_{2} T_{2+} m_{2}\left(T_{2}\right)\right)}+\ldots
\end{aligned}
$$

Eq. (5) represents the sum of economic returns under the presence of catastrophic risk associated with an infinite number of successive timber crops. Rearranging Eq. (5), we obtain: 


$$
\begin{aligned}
L E V_{1}= & -C_{0}+\sum_{i=1}^{\infty}\left[P_{i}\left(T_{i}\right) Q\left(t_{i}\right)-C_{i}+\right. \\
& \left.e^{\left(r_{i} T i_{+} m_{i}\left(T_{i}\right)\right)} \int_{0}^{T_{i}} \lambda_{i}\left(X_{i}\right)\left[\bar{g}_{i}\left(X_{i}\right) P_{i}\left(X_{i}\right) Q\left(X_{i}\right) C_{i}\right] e^{-\left(r_{i} X_{i+} m_{i}\left(X_{i}\right)\right)} d X_{i}\right] e^{-\sum_{j=1}^{i}\left(r_{j} T_{j}+m_{j}\left(T_{j}\right)\right)(6}
\end{aligned}
$$

Defining $\emptyset_{i}=\lambda_{i}\left(X_{i}\right)\left[\bar{g}_{i}\left(X_{i}\right) P_{i}\left(X_{i}\right) Q\left(X_{i}\right)-C_{i}\right] e^{-\left(r_{i} X_{i+} m_{i}\left(X_{i}\right)\right)}$, Eq. (5) can be expressed as:

$$
\begin{aligned}
L E V_{1}= & -C_{0}+\left[P_{1}\left(T_{1}\right) Q_{1}\left(T_{1}\right)-C_{1}+e^{\left(r_{1} T_{1+} m_{1}\left(T_{1}\right)\right)} \int_{0}^{T_{1}} \emptyset_{1} d X_{1}\right] e^{-\left(r_{1} T_{1+} m_{1}\left(T_{1}\right)\right)}+ \\
& e^{-\left(r_{1} T_{1+} m_{1}\left(T_{1}\right)\right)}\left\{\sum _ { i = 2 } ^ { \infty } \left[P_{i}\left(T_{i}\right) Q\left(T_{i}\right)-C_{i}+\right.\right. \\
& \left.\left.e^{\left(r_{i} T_{i+} m_{i}\left(T_{i}\right)\right)} \int_{0}^{T_{i}} \emptyset_{i} d X_{i}\right] e^{-\left(\sum_{j=2}^{i}\left(r_{j} T_{j}+m_{j}\left(T_{j}\right)\right)\right.}\right\} \\
L E V_{1}= & -C_{0}+\left[\mathrm{P}_{1}\left(T_{1}\right) Q_{1}\left(T_{1}\right)+e^{\left(r_{1} T_{1+} m_{1}\left(T_{1}\right)\right)} \int_{0}^{T_{1}} \emptyset_{1} d X_{1}\right] e^{-\left(r_{1} T_{1+} m_{1}\left(T_{1}\right)\right)}+ \\
& e^{-\left(r_{1} T_{1+} m_{1}\left(T_{1}\right)\right)}\left[-C_{1}+\left\{\sum _ { i = 2 } ^ { \infty } \left[P_{i}\left(T_{i}\right) Q\left(T_{i}\right)-C_{i}+\right.\right.\right. \\
& \left.\left.\left.e^{\left(r_{i} T_{i+} m_{i}\left(T_{i}\right)\right)} \int_{0}^{T_{i}} \emptyset_{i} d X_{i}\right] e^{-\left(\sum_{j=2}^{i}\left(r_{j} T_{j}+m_{j}\left(T_{j}\right)\right)\right.}\right\}\right]
\end{aligned}
$$

The expression between [ ] of the third component on the right hand side (RHS) of Eq. (8), represents the land expectation value of the second timber crop, which we define as $L E V_{2}$. Thus:

$$
\begin{aligned}
L E V_{1}= & -C_{0}+\left[P_{1}\left(T_{1}\right) Q_{1}\left(T_{1}\right)+e^{\left(r_{1} T_{1+} m_{1}\left(T_{1}\right)\right)} \int_{0}^{T_{1}} \emptyset_{1} d X_{1}\right] e^{-\left(r_{1} T_{1+} m_{1}\left(T_{1}\right)\right)}+ \\
& e^{-\left(r_{1} T_{1+} m_{1}\left(T_{1}\right)\right)} L E V_{2}
\end{aligned}
$$

Intuitively, Eq. (9) reflects a link between the land values of successive timber crops i.e., $L E V_{2}$ would also depend on $L E V_{3}$ and so on. The solution for this recursive problem may seem daunting to obtain since it would require information about both current and all future timber crops. However, if we consider $L E V_{2}$ as single number, Eq. (9) can be easily solved. The main advantage of analytically solving this recursive problem is that a vast number of $L E V_{2}$ values can be used to 
quickly examine the optimal forest management implications for different $L E V_{2}$ values (Chang, 1998).

\section{Economic implications of the generalized Reed model on the optimal harvest age}

To explore the optimal conditions for the optimal harvest age, Eq. (8) can be reformulated

as:

$$
\begin{aligned}
L E V_{1}= & -C_{0}+\sum_{i=1}^{k-1}\left\{P_{i}\left(T_{i}\right) Q_{i}\left(T_{i}\right)-C_{i}+e^{\left(r_{i} T i_{+} m_{i}\left(T_{i}\right)\right)} \int_{0}^{T_{i}} \emptyset_{i} d X_{i}\right\} e^{-\sum_{j=1}^{i}\left(r_{j} T_{j}+m_{j}\left(T_{j}\right)\right)}+ \\
& \left\{P_{k}\left(T_{k}\right) Q_{k}\left(T_{k}\right)-C_{k}+e^{\left(r_{k} T_{k+} m_{k}\left(T_{k}\right)\right)} \int_{0}^{T_{k}} \emptyset_{k} d X_{k}\right\} e^{-\sum_{j=1}^{k}\left(r_{k} T_{k+} m_{k}\left(T_{k}\right)\right)}+ \\
& \sum_{i=k+1}^{\infty}\left\{\left[P_{i}\left(T_{i}\right) Q\left(T_{i}\right)-C_{i}\right]+e^{\left(r_{i} T i_{+} m_{i}\left(T_{i}\right)\right)} \int_{0}^{T_{i}} \emptyset_{i} d X_{i}\right\} e^{-\sum_{j=1}^{i}\left(r_{j} T_{j}+m_{j}\left(T_{j}\right)\right)}
\end{aligned}
$$

The optimal harvest age is given by maximizing the value of $L E V_{1}$, therefore Eq. (10) is differentiated with respect to $T_{k}$ for any $\mathrm{kth}$ timber crop and set to equal 0 . We follow two main assumptions regarding the volume function of the forest stand $Q(t)$ (Amacher et al., 2009): first, it is an increasing function of time until the biological age at which a forest reaches its biological maturity and subsequently decreases with stand age, i.e., $\frac{\partial Q(T)}{\partial T}>0$ for $T \leq T_{a}$ and $\frac{\partial Q(T)}{\partial T}<0$ for $T>T_{a}$, where $T_{a}$ is the maturity age of the forest. Second, the forest stand initially increases in volume at an increasing rate until the inflection point at which time it increases at a decreasing rate, i.e., $\frac{\partial^{2} Q(T)}{(\partial T)^{2}}>0$ for $T<T_{o}$ and $\frac{\partial^{2} Q(T)}{(\partial T)^{2}}<0$ for $T>T_{o}$, where $T_{o}$ is the inflection point of the forest growth function. Thus: 


$$
\begin{aligned}
\frac{\partial L E V_{1}}{\partial T_{k}}= & \left\{\frac{\partial P_{k}\left(T_{k}\right)}{\partial T_{k}} Q_{k}\left(T_{k}\right)+P_{k}\left(T_{k}\right) \frac{\partial Q_{k}\left(T_{k}\right)}{\partial T_{k}}+\left(r_{k}+\lambda_{k}\left(T_{k}\right)\right) e^{\left(r_{k} T_{k+} m_{k}\left(T_{k}\right)\right) \int_{0}^{T_{k}} \emptyset_{k} d X_{k}+}\right. \\
& \left.e^{\left(r_{k} T_{k+} m_{k}\left(T_{k}\right)\right)} \emptyset_{k}\right\} e^{-\sum_{j=1}^{k}\left(r_{j} T_{j}+m_{j}\left(T_{j}\right)\right)}-\left\{P_{k}\left(T_{k}\right) Q_{k}\left(T_{k}\right)-C_{k}+\right. \\
& \left.e^{\left(r_{k} T_{k+} m_{k}\left(T_{k}\right)\right)} \int_{0}^{T_{k}} \emptyset_{k} d X_{k}\right\}\left(r_{k}+\lambda_{k}\left(T_{k}\right)\right) e^{-\sum_{j=1}^{k}\left(r_{j} T_{j}+m_{j}\left(T_{j}\right)\right)}- \\
& \sum_{i=k+1}^{\infty}\left\{\left[P_{i}\left(T_{i}\right) Q_{i}\left(T_{i}\right)-C_{i}\right]+e^{\left(r_{i} T_{i}+m_{i}\left(T_{i}\right)\right)} \int_{0}^{T_{i}} \emptyset_{i} d X_{i}\right\}\left(r_{k}+\right. \\
& \left.\lambda_{k}\left(T_{k}\right)\right) e^{-\sum_{j=1}^{i}\left(r_{j} T_{j}+m_{j}\left(T_{j}\right)\right)}=0
\end{aligned}
$$

Let $V_{k}$ be the stumpage value, where $V_{k}\left(T_{k}\right)=\left[P_{k}\left(T_{k}\right) Q_{k}\left(T_{k}\right)\right]$ and $\frac{\partial V_{k}\left(T_{k}\right)}{\partial T_{k}}=$

$$
\begin{aligned}
& \frac{\partial P_{k}\left(t_{k}\right)}{\partial T_{k}} Q_{k}\left(T_{k}\right)+P_{k}\left(t_{k}\right) \frac{\partial Q_{k}\left(T_{k}\right)}{\partial T_{k}} \text {. Thus, rearranging Eq. (14), we obtain: } \\
& \frac{\partial L E V_{1}}{\partial T_{k}}=\left\{\frac{\partial V_{k}\left(T_{k}\right)}{\partial T_{k}}+\left(r_{k}+\lambda_{k}\left(T_{k}\right)\right) e^{\left(r_{k} T_{k+} m_{k}\left(T_{k}\right)\right)} \int_{0}^{T_{k}} \emptyset_{k} d X_{k}+e^{\left(r_{k} T_{k+} m_{k}\left(T_{k}\right)\right)} \emptyset_{k}\right\}- \\
& \\
& \left\{V_{k}\left(T_{k}\right)-C_{k}+e^{\left(r_{k} T_{k+} m_{k}\left(T_{k}\right)\right)} \int_{0}^{T_{k}} \emptyset_{k} d X_{k}\right\}\left(r_{k}+\lambda_{k}\left(T_{k}\right)\right)- \\
& \sum_{i=k+1}^{\infty}\left\{P_{i}\left(T_{i}\right) Q_{i}\left(T_{i}\right)-C_{i}+e^{\left(r_{i} T_{i}+m_{i}\left(T_{i}\right)\right)} \int_{0}^{T_{i}} \emptyset_{i} d X_{i}\right\}\left(r_{k}+\right. \\
& \left.\lambda_{k}\left(T_{k}\right)\right) e^{-\sum_{j=k+1}^{i}\left(r_{j} T_{j}+m_{j}\left(T_{j}\right)\right)}=0
\end{aligned}
$$

Eq. (12) could be rewritten as:

$$
\begin{gathered}
\frac{\partial V_{k}\left(T_{k}\right)}{\partial T_{k}}+e^{\left(r_{k} T_{k+} m_{k}\left(T_{k}\right)\right)} \emptyset_{k}-\left(r_{k}+\lambda_{k}\left(T_{k}\right)\right)\left[V_{k}\left(T_{k}\right)-C_{k}\right]- \\
\left(r_{k}+\lambda_{k}\left(T_{k}\right)\right) \sum_{i=k+1}^{\infty}\left\{P_{i}\left(T_{i}\right) Q_{i}\left(T_{i}\right)-C_{i}+e^{\left(r_{i} T_{i}+m_{i}\left(T_{i}\right)\right)} \int_{0}^{T_{i}} \emptyset_{i} d X_{i}\right\} e^{-\sum_{j=k+1}^{i}\left(r_{j} T_{j}+m_{j}\left(T_{j}\right)\right)}= \\
\frac{\partial V_{k}\left(T_{k}\right)}{\partial T_{k}}+e^{\left(r_{k} T_{k+} m_{k}\left(T_{k}\right)\right)} \emptyset_{k}=\left(r_{k}+\lambda_{k}\left(T_{k}\right)\right) V_{k}\left(T_{k}\right)+\left(r_{k}+\lambda_{k}\left(T_{k}\right)\right)\left[-C_{k}+\right. \\
\sum_{i=k+1}^{\infty}\left\{P_{i}\left(T_{i}\right) Q_{i}\left(T_{i}\right)-C_{i}+\right. \\
\left.\left.e^{\left(r_{i} T_{i}+m_{i}\left(T_{i}\right)\right)} \int_{0}^{T_{i}} \emptyset_{i} d X_{i}\right\} e^{-\sum_{j=k+1}^{i}\left(r_{j} T_{j}+m_{j}\left(T_{j}\right)\right)}\right]
\end{gathered}
$$


Eq. (14) can be expressed in a compact form, for any $\mathrm{k}$, as:

$$
\frac{\partial V_{k}\left(T_{k}\right)}{\partial T_{k}}+e^{\left(r_{k} T_{k+} m_{k}\left(T_{k}\right)\right)} \emptyset_{k}=\left(r_{k}+\lambda_{k}\left(T_{k}\right)\right) V_{k}\left(T_{k}\right)+\left(r_{k}+\lambda_{k}\left(T_{k}\right)\right) L E V_{k+1}
$$

The left hand side (LHS) of Eq. (15) represents the net marginal revenue of the stand by waiting one extra year. It includes earnings due to the growth in stand stumpage value $\frac{\partial V_{k}\left(T_{k}\right)}{\partial T_{k}}$ and the marginal return due to salvage $e^{\left(r_{k} T_{k+} m_{k}\left(T_{k}\right)\right)} \emptyset_{k}$. The right hand side (RHS) of Eq. (15) represents the marginal cost of waiting one extra year, including the cost of holding the stand (interest earned on the stumpage value $\left.\left(r_{k}+\lambda_{k}\left(T_{k}\right)\right) V_{k}\left(T_{k}\right)\right)$ and the cost of holding the land (interest earned on the future land value $\left.\left(r_{k}+\lambda_{k}\left(T_{k}\right)\right) L E V_{k+1}\right)$. Eq. (15) provides a harvesting rule: the optimal harvest age is reached when both sides of the equation are equal. Thus, if the marginal revenue of waiting one extra year were equal to or less than the marginal cost of waiting one extra year, the landowner should harvest the forest stand. If the marginal revenue of waiting one extra year were higher than the marginal cost of waiting one extra year, the landowner should wait for another time period.

According to Eq. (15), the optimal harvesting decision for the $k$ th timber crop would depend on the values of future timber crops as reflected in $L E V_{k+1}$. It acts as a threshold value to determine a forest landowner's harvesting decision. We will denote this threshold value as $\varphi\left(T_{k}\right)$. Future land values could be considered a single number or a range of numbers obtained from local transactions evidence (Chang, 1998). By rearranging Eq. (15) we have $\varphi\left(T_{k}\right)=$ $\frac{\frac{\partial V_{k}\left(T_{k}\right)}{\partial T_{k}}+e^{\left(r_{k} T_{k+} m_{k}\left(T_{k}\right)\right)} \emptyset_{k}-\left(r_{k}+\lambda_{k}\left(T_{k}\right)\right) V_{k}\left(T_{k}\right)}{\left(r_{k}+\lambda_{k}\left(T_{k}\right)\right)}$. Thus a landowner would let the forest stand grow one extra year if $L E V_{k+1}<\varphi\left(T_{k}\right)$. From Eq. (15) we observe that the current and future probability of risk of a fire and salvageable portion impact the current optimal harvest age. The mathematical 
proofs for the comparative static analyses can be found in Appendix A. The comparative static analysis for the other parameters can be found in Chang (1998). Interested readers could follow the mathematical proofs therein for the other parameters and examine how they impact the optimal harvest age ${ }^{5}$. As stated previously, we have assumed a rising risk of wildfires for this generalized model. When the wildfire arrival does not depend on the stand age, the risk of wildfires is described by a Poisson parameter $\lambda$. In this case, Eq. (15) takes the following form:

$$
\frac{\partial V_{k}\left(T_{k}\right)}{\partial T_{k}}+e^{\left(r_{k+} \lambda_{k}\right) T_{k+}} \emptyset_{k}=\left(r_{k}+\lambda_{k}\right) V_{k}\left(T_{k}\right)+\left(r_{k}+\lambda_{k}\right) L E V_{k+1}
$$

The comparative statics of changes in current and future constant probability of wildfires can be also found in Appendix B.

\section{Application to Southern U.S. forestlands}

We apply the generalized Reed model to even-aged slash pine stands in the context of wildfire risk. As one of the main commercial species in the southern U.S., slash pine has been planted on more than 4.2 million ha, covering a wide range from eastern Texas to southern North Carolina to south-central Florida (Barnett and Sheffield, 2004). The risk of fires is considered one of the major natural disturbances to forest ecosystems in the U.S. South affecting standing timber and having environmental consequences (Liu et al., 2014). On average, around 36,500 wildfires burned 594,000 ha in the southern U.S. between 2005 and 2014 (Natural Interagency Coordination Center, 2014). The 1998 wildfires in Florida burned around 200,000 ha of forests caused economic

\footnotetext{
${ }^{5}$ Increased risk of fires would shorten harvest ages under the Reed model (Amacher et al., 2009; Reed, 1984). Increased salvageable portions would lead to longer harvest ages (Amacher et al., 2009; Reed, 1984; Reed and Errico 1985).
} 
losses between $\$ 322$ and $\$ 509$ million to the softwood timber market (Butry et al., 2000). The Bugaboo fire in 2007 affected over 240,000 ha of forests in Georgia and Florida (Stanturf and Goodrick, 2013). Smoke associated to wildfires decreases air quality and adversely affects human health (Liu et al., 2014). Wildfires have become a serious threat to people and their properties since more people are living in or around wildland-urban interface areas (Stein et al., 2013). Wildfires also have negative impacts on soil (reduction of nutrient availability due to volatilization and leaching) and water quality (increased sediment loading) (Liu et al., 2014). Furthermore, a longterm trend increased wildfires due to climate change may lead to major changes in forest biodiversity and carbon dynamics (Mitchell et al., 2014).

In our analysis, we have considered that a forest stand faces a rising probability of fire risk and that any salvageable timber after a wildfire is harvested. After a wildfire, a forest stand is replanted to start a new rotation. Following Amacher et al. (2005) we model the probability of fire using a triangular distribution. The triangular distribution is typically used when there is a lack of information about the relationship between the stand age and probability of fire (Amacher et al., 2005; Li et al., 1997). Thus:

$$
\lambda(X)=2 t_{o} \frac{\left(X-t_{a}\right)}{\left(t_{b}-t_{a}\right)\left(t_{c}-t_{a}\right)}
$$

where is $t_{b}$ and $t_{a}$ are, respectively, the upper and lower limit of time $X, t_{c}$ is the mode vale and $t_{o}$ is a scale parameter. This scale parameter represents a shift in the magnitude of the fire arrival $\lambda(X)$. Typical wildfire frequency in the southern U.S. ranged between 0 and 35 years (Stein et al., 2013). Major wildfires occur every 50 years but they are expected to be more frequent, with longer fire seasons with warmer temperatures (Stanturf and Goodrick, 2013). We have assumed a wildfire frequency every 50 years, a value that falls within the range of wildfire arrivals in the southern 
U.S. Thus $t_{a}=0$, and $t_{b}=t_{c}=50$. We set $t_{o}=1$. Increased values of this parameter represent linear increased in the fire arrival path (Amacher et al., 2005). Given future changing climatic conditions, we also evaluate an increase in the probability of a risk of wildfire. Thus, we simulate an increase in wildfire risk to $t_{o}=3$ to gauge the implication of an increased $\lambda(X)$ on the GRM. We assume two contrasting salvageable portions ${ }^{6}, g=0$ (full destruction) and $g=1$ (full salvage), to reflect the wide spectrum of empirical evidence of salvage after a wildfire.

Finally, we relax the assumption of rising risk of wildfire assuming a constant arrival rate $\lambda$, i.e., the fire arrival does not depend on the age of the forest stand. This is represented by Eq. (16), and the constant probability of wildfire arrival can be represented as $\lambda=\frac{t_{o}}{\left(t_{b}-t_{a}\right)}$. Thus, we compare the impacts of increased rising fire arrival and constant fire arrival on the optimal slash pine management.

We use growth and yield models developed by (Pienaar et al., 1996) to quantify the merchantable volume of managed slash pine stands. Three main product classes are defined: sawtimber, chip-and-saw and pulpwood. Southern average price of sawtimber, chip and saw, and pulpwood are $\$ 30.5 \mathrm{~m}^{-3}, \$ 20.5 \mathrm{~m}^{-3}$ and $\$ 13.1 \mathrm{~m}^{-3}$, respectively (Timber Mart-South, 2014). We employed regional stumpage prices for 2014 , which was the most recent data available at the time of our analysis. These prices serve as a starting point for testing the impacts of wildfire risk and

\footnotetext{
${ }^{6}$ During the 1998 wildfires in Florida, landowners were able to salvage $24 \%$ of the pine volume (Butry et al., 2000). Amacher et al. (2005) have modeled proportions of timber salvage between $67 \%$ and $90 \%$ after wildfires, based on characteristics of the forests such as planting density and intermediate fuel treatment.
} 
salvageable portion on the harvesting decision ${ }^{7}$. Regardless of the stumpage prices used (e.g., 2014), the implications of these two parameters should hold with respect to the directional effect on the optimal harvest age. Note that we do not included the effect of stumpage prices on the current harvest age, since that has been well-examined by Chang (1998) in his generalized Faustmann model. The site index and stand density are assumed to be $22 \mathrm{~m}$ and 1500 trees $^{-1}$, respectively. Costs associated with the establishment of slash pine stands are set to $\$ 1015.4$ ha $^{-1}$ (Dooley and Barlow, 2013). The real discount rate is set to $3 \%$.

\section{Results}

\subsection{LEV, threshold land values, and optimal harvest age}

Land expectation value ( $L E V)$, threshold land values and optimal harvest age for different levels of wildfire risks and salvageable portions are illustrated in Table 2. A landowner would let the forest stand grow one extra year if future land value $L E V_{k+1}<\varphi\left(T_{k}\right)$. For example, for risk level $t_{o}=1$ and salvageable portion $g=0.5$, and with the presence of fire risk (Table $2 \mathrm{a}$ ), at age 25 years, a landowner would let the forest stand grow one extra year if the future land value $L E V_{k+1}<$ $\$ 1119.2 \mathrm{ha}^{-1}$. At age 24 years, the landowner should wait until age 25 years to make the decision of harvesting under fire risk, as long as the $L E V_{k+1}<\$ 1756.6 \mathrm{ha}^{-1}$. Therefore, the optimal harvest

\footnotetext{
${ }^{7}$ Stochastic variations of stumpage prices due to economic conditions will certainly impact the optimal forest management- in the Southeastern U.S, the average variation of real stumpage prices between 1981-2014 is around 18\% of the average mean value for the same period (Timber Mart South, 2014). However, our model only allows stumpage prices to fluctuate as different proportions of sawtimber, chip and saw, and pulpwood are produced by the forest stand as it ages.
} 
age would be at ages 25 and 24 years if the future land values $L E V_{k+1}$ ranged, respectively, between the threshold values $\varphi\left(T_{k}\right)$ of $\$ 1119.2 \mathrm{ha}^{-1}$ and $\$ 1756.6 \mathrm{ha}^{-1}$, and $\$ 1756.6 \mathrm{ha}^{-1}$ and $\$ 2424.1$ $\mathrm{ha}^{-1}$. Under the traditional Reed model, the optimal harvest age is 25 years with a $L E V$ of $\$ 1517.6$ $\mathrm{ha}^{-1}$.

\section{Place Table 2 approximately here}

\subsection{The effect of changes in risk of wildfires $\lambda$}

The impacts of changes in risk of fire on the $L E V$ and optimal harvest ages are also empirically explored by varying this parameter ceteris paribus. We present the rationale for our numerical analysis and test the comparative static analysis for wildfire risk under the GRM below. See Appendix A for the formal mathematical proofs.

We begin with low fire risk $\left(t_{o}=1\right)$ and high salvageable portion $g=0.5$ as the base case. Under this combination for both the current and future timber crops, the optimal harvest age would be 25 years for the current timber crop with a land expectation value of $\$ 1517.6 \mathrm{ha}^{-1}$ under the traditional Reed model (Table 2a). If the fire risk increases to $t_{o}=3$, the land expectation values and the optimal harvest ages would be $\$ 634.9 \mathrm{ha}^{-1}$ and 23 years, under the classical Reed model.

Under the generalized Reed model, if future fire risk increases to $t_{o}=3$, the $\$ 634.9 \mathrm{ha}^{-1}$ future land expectation value influences the optimal harvest age for the current stand. The optimal harvest age for the current stand would be lengthened one year to 26 years from 25 years since the $\$ 634.9 \mathrm{ha}^{-1}$ future land value would fall within the threshold values of $\$ 517.9$ and $\$ 1119.2 \mathrm{ha}^{-1}$ for 
the current $\operatorname{stand}^{8}$ (Fig. 1). Higher future fire risk would lengthen the optimal harvest age for the current timber crop. Higher probabilities of fire risk on future forest stands would decrease the value of $L E V_{k+1}$. Eq. (15) would only hold by reducing $\frac{\partial V_{k}\left(T_{k}\right)}{\partial T_{k}}$, i.e., lengthening the harvest age. This makes sense since a landowner would realize higher economic returns by extending the harvest decision for the current forest stand in light of lower future land values given by increased future fire risks.

On the other hand, if the current fire risk increases to $t_{o}=3$ while future risks stay at $t_{o}=$ 1, the optimal harvest age for the current timber crop would drop from 23 years to 21 years, because the $\$ 1517.6 \mathrm{ha}^{-1}$ future land value would fall between $\$ 1174.4$ and $\$ 1688.9$ ha $^{1}$ (Fig. 1). Higher current fire risk would shorten the optimal harvest age for the current timber crop. An increase in the probability of wildfire risk for the current stand would increase both the LHS $\left(e^{\left(r_{k}+\lambda_{k}\right) T_{k}} \emptyset_{k}\right)$ and RHS $\left(\left(r_{k}+\lambda_{k}\right) V_{k}\left(T_{k}\right)\right.$ and $\left.\left(r_{k}+\lambda_{k}\right) L E V_{k+1}\right)$ of Eq. (15), with the value of the RHS increasing more than the LHS. To restore equality $\frac{\partial V_{k}\left(T_{k}\right)}{\partial T_{k}}$ must also increase, implying a shortened harvest age.

\section{Place Fig.1 approximately here}

\subsection{The effect of changes in salvageable portion $g$}

Similar to the previous case, we vary the salvageable portion to quantify the impact of this parameter on the $L E V$ and optimal harvest age (mathematical proofs can be also found in Appendix A). We begin with low risk $\left(t_{o}=1\right)$ and a salvageable portion $g=0$ (all trees are destroyed by a

\footnotetext{
${ }^{8}$ Changes in the optimal current harvest age due to increases in fire risks (or any parameter) for future or current timber crops would depend on if $L E V_{k+1}<\varphi\left(T_{k}\right)$. Since $\varphi\left(T_{k}\right)$ varies as stand ages, changes in the harvest age are specific for a particular $T_{k}$ chosen as the base case.
} 
wildfire) as the base case. Under this combination the land expectation value is $\$ 1408.9 \mathrm{ha}^{-1}$ and the optimal harvest age is 24 years. Under the traditional Reed approach, if salvageable portions increases to $g=1$ (all trees are salvaged), the land expectation value and optimal harvest age are $\$ 1647.9 \mathrm{ha}^{-1}$ and 26 years (Table 2b).

Under the GRM, if all future salvageable portions increases to $g=1$, the optimal harvest age is shortened to 23 years since the $\$ 1647.9 \mathrm{ha}^{-1}$ land value would fall between the threshold values of $\$ 1613.2$ and $\$ 2377.8$ ha $^{-1}$ (Fig. 2). Higher future level of salvageable portions would increase future land values $L E V_{k+1}$ in Eq. (15) leading to shorter harvest ages for the current timber crop. Intuitively, a landowner would bring forward the current harvest and replant to realize future higher economic returns associated with higher salvageable portions.

An increase in the current salvageable portion to $g=1$ while future portions stay low at $g$ $=0$ would extend the current harvest age. The $\$ 1408.9 \mathrm{ha}^{-1}$ future land value would fall between the threshold values of $\$ 1060.8$ and $\$ 1552.0 \mathrm{ha}^{-1}$, extending the current harvest age from 26 years to 27 years (Fig. 2). The impact of a higher salvageable portion for the current stand would increase the marginal net revenue by raising only the value of $e^{\left(r_{k}+\lambda_{k}\right) T_{k}} \emptyset_{k}$ on the LHS of Eq. (15). To retain equality $\frac{\partial V_{k}\left(T_{k}\right)}{\partial T_{k}}$ should decrease, lengthening the harvest age.

\section{Place Fig. 2 approximately here}

\subsection{Rising risk vs constant risk of wildfires}

Table 3a shows the $L E V$ s for slash pine assuming different levels of constant wildfire risks $\lambda\left(\lambda=t_{o} / 50\right)$ and salvageable portion $\mathrm{g}=0.5$. The optimal harvest ages for $\lambda=0.02\left(t_{o}=1\right)$ is 25 years for the traditional Reed model. In the case of $\lambda=0.04\left(t_{o}=2\right)$, the optimal harvest age is 24 years. Under the GRM, a distinctive feature of the rising wildfire risk scenarios is the aggregate level of wildfire risk $m(X)$. To compare the impacts of rising and constant wildfire risk it is 
necessary to adjust the scale parameter $t_{o}$ in order to have a similar aggregate level of wildfire risk. In the case of a constant wildfire risk, for $t_{o}=1(\lambda=0.02)$, a similar aggregate level of risk $m(X)$ would be $0.5-$ the cumulative sum of $\lambda$ until the optimal harvest age, i.e., $0.02 * 25$. For $t_{o}=$ $2(\lambda=0.04)$, the aggregate level of risk $m(X)$ would be $0.96(24 * 0.04)$, respectively. Thus, we use the following adjusted scale parameters $t_{o}=1.9$ and 4 for the rising wildfire risk case to approximately mirror the aggregate levels of risk 0.5 and 0.96 , respectively, for the constant risk scenario. For adjusted $t_{o}=1.9$ and 4 , the land values are $\$ 1010.0$ and $\$ 398.6 \mathrm{ha}^{-1}$, respectively, under the traditional Reed model (Table 3b).

\section{Place Table 3 approximately here}

Under the generalized model, increases in future rising wildfire risks have less impact than increases in future constant wildfire risks on the optimal harvest ages for the current crop. Assuming a land expectation value of $\$ 1010.0 \mathrm{ha}^{-1}$ and optimal harvest age of 24 years as the base case (adjusted $t_{o}=1.9$ ), the optimal harvest age would increase by one year with an increase in the future fire risk to $t_{o}=4$. Since future land expectation value $\$ 398.6 \mathrm{ha}^{-1}\left(t_{o}=4\right)$ falls between the threshold values of $\$ 11.9$ and $\$ 537.6 \mathrm{ha}^{-1}$, the optimal harvest age increases from 24 to 25 years (Table 3b). Assuming a harvest age of 25 years and a land value of $\$ 1570.7 \mathrm{ha}^{-1}$ for the constant wildfire risk case, the optimal harvest age is extended two years for the equivalent scale parameter $t_{o}=2$. With $t_{o}=2$, the associated land expectation values is $\$ 167.0 \mathrm{ha}^{1}$ which falls between the threshold values of $\$ 60.3$ and $577.2 \mathrm{ha}^{-1}$, respectively, increasing the optimal harvest age to 27 years (Table $3 a)$.

Increases in the current rising risk of wildfires have a similar impact on the optimal harvest age compared to increases in the current constant risk of wildfires. Let's consider future land values of $\$ 1010.0 \mathrm{ha}^{-1}\left(t_{o}=1.9\right)$ and $\$ 1570.7 \mathrm{ha}^{-1}\left(t_{o}=1\right)$ as the base cases for rising and constant risk 
of wildfires, respectively. With an increase in the current rising risk to adjusted $t_{o}=4$, the future land value of $\$ 1010.0 \mathrm{ha}^{-1}$ falls between the threshold values of $\$ 1006.0$ and $\$ 1465.2 \mathrm{ha}^{-1}$ and the optimal harvest age for the current timber crop would drop two years from 22 to 20 years (Table $3 \mathrm{~b}$ ). With increased $t_{o}=2$ for the constant risk case, the land value of $\$ 1570.7 \mathrm{ha}^{-1}$ falls between \$1269.4 and \$1718.5 $\mathrm{ha}^{-1}$ and the optimal harvest age would also drop two years from 24 to 22 years (Table 3a).

\section{Conclusions and recommendations}

The traditional Reed model determines the impact of current disturbance risk on the current harvest age. However, this model cannot be used to determine the impact of future disturbance risk on the current harvesting decision. We extend the traditional Reed model by allowing stumpage prices, regeneration cost, stand volume, probability of catastrophic events, and salvageable portion to fluctuate over time. This model allows us to determine analytically the impacts of these parameters on land values and optimal harvest age, and indirectly timber supply.

We evaluate and discuss the impact of two particularly important factors that may drive harvest decisions in terms of a natural disaster such as fires-risk and salvageable portion-on optimal harvesting decisions. We apply the generalized Reed model to a representative even-aged slash pine plantation. Comparative static analysis presented in this paper show that these two main parameters have countervailing impacts on the optimal harvest decision. Risk is allowed to vary as trees age, with current risk and future risk of wildfires defined separately. Increases in the current risk of wildfire-related losses would shorten the predicted optimal harvest age. Higher future risks, however, would have the opposite impact-lengthening the optimal rotation. With increasing trends in fire risk and consequently low profitability of future timber crops, the optimal 
harvest age will always be longer in current timber crops than the traditional Reed model predicts. A similar approach is applied to the salvageable portion, and we find that increases in the current salvageable portion would lengthen the harvest age, while higher future salvageable portions would reduce the harvest age.

We also compare the effect of fire risk on the optimal harvest age between a rising and constant fire arrival path. Regardless of the fire arrival path, the current optimal harvest age increases/decreases with increased future/current wildfire risk. If future wildfire arrival rates rise with stand age, the optimal current harvest age also rises but remains below the current optimal harvest age associated with future constant wildfire arrival rates. When we increase both the current probability of wildfire risk either for the rising or the constant wildfire arrival rate, the optimal harvest age falls in the same magnitude for both scenarios. Therefore, the flexibility of our extended Reed model provides greater insight, i.e. a more realistic simulation of true harvest decision making, within the context of the economic consequences of natural hazards (e.g., fires). This tool can also be a valuable supportive tool for forest policy decision-making, which typically aims to mitigate the negative economic effects of wildfires - as in the case of timber crops with more fire-resistant forest species that yield higher economic returns (e.g. longleaf pine).

Policy instruments that incentivize forest landowners to undertake intermediate wildfire treatments become critical to reduce the risk of wildfires. Particularly in the cases of rising wildfire risk or constant but high wildfire risk, intermediate treatments are effective practices to increase the optimal harvest age and realize large economic profits (Amacher et al., 2005). Further research into risk of natural hazards and links with policy instruments would be an interesting addition to the literature, and would provide valuable information for management of forest resources. 
Our findings also suggest several additional questions and applications of the generalized Reed model. It can be used to analyze any disturbance risk that follows a non-homogenous Poisson distribution such as pests, droughts and flooding. Furthermore, the inclusion of wildfire intensity and modelling salvage efforts as a function of silvicultural treatments are also plausible extensions of our model. Our analysis can be further extended to other even-aged, highly productive, forest types such as Douglas Fir (Pseudotsuga menziesii (Mirb.) Franco) stands in the Pacific Northwest, which is an important area for future work. These western forests are more wildfire-prone and have longer harvest ages, so they face long-run key challenges, such as increasing their value and changing their optimal forest management to generate more competitive yields under wildfire risk (Talbert and Marshall, 2005). The incorporation of non-timber benefits such as biodiversity and recreational values would allow the model to assess broader social welfare impacts, which is an approach that may be particularly important for public land management following disasters. Adding environmental goods and services to the model would allow application to non-industrial private forest landowners who may manage for multiple environmental benefits rather than maximize timber profits. The inclusion of the net benefits of a natural disturbance risk insurance system for future timber crops to our model may enhance the financial stability of forest management. We also assume risk neutrality in the model. Stochastic stumpage prices should change the optimal rotation for risk-averse or risk-neutral landowners depending on interest rates and regeneration costs (Gong and Löfgren, 2008). Finally, the economic assessment of timber crops with a different stand structure (uneven aged forests) to reduce the impact of fires may be also another application of this model. 


\section{Acknowledgements}

This work is part of the Pine Integrated Network: Education, Mitigation, and Adaptation project (PINEMAP) and supported by the USDA National Institute Food and Agriculture (NIFA), award \#2011-68002-30185. 


\section{Appendix A. Comparative static conditions for the rising wildfire risk}

In order to derive the mathematical proofs for the impact of current and future parameters of the GRM on the current rotation age of a forest stand we reformulate the first order condition for Eq. (15):

$$
\begin{aligned}
U=\frac{\partial L E V_{1}}{\partial T_{k}}= & \frac{\partial V_{k}\left(T_{k}\right)}{\partial T_{k}}+e^{\left(r_{k} T_{k+} m_{k}\left(T_{k}\right)\right)} \emptyset_{k}-\left(r_{k}+\lambda_{k}\left(T_{k}\right)\right) V_{k}\left(T_{k}\right) \\
& -\left(r_{k}+\lambda_{k}\left(T_{k}\right)\right) L E V_{k+1}
\end{aligned}
$$

Recall that $e^{\left(r_{k} T_{k+} m_{k}\left(T_{k}\right)\right)} \emptyset_{k}=\lambda_{k}\left(T_{k}\right)\left[\bar{g}_{k}\left(T_{k}\right) V_{k}\left(T_{k}\right)-C_{k}\right]$. We also derive the total derivative of $U$ with respect to each parameter. For example, in the case of the discount rate $r_{k}$, the total derivative of $U$ yields:

$$
d U=\frac{\partial U}{\partial T_{k}} d T_{k}+\frac{\partial U}{\partial r_{k}} d r_{k}=0, \text { or } \frac{d T_{k}}{d r_{k}}=-\left(\frac{\partial U}{\partial r_{k}} / \frac{\partial U}{\partial T_{k}}\right)
$$

Furthermore,

$$
\begin{aligned}
\frac{\partial U}{\partial T_{k}}= & \frac{\partial^{2} V_{k}\left(T_{k}\right)}{\left(\partial T_{k}\right)^{2}}-\lambda_{k}\left(T_{k}\right)\left[\left(1-\bar{g}_{k}\left(T_{k}\right)\right) \frac{\partial V_{k}\left(T_{k}\right)}{\partial T_{k}}\right]-\frac{\partial \lambda_{k}\left(T_{k}\right)}{\partial T_{k}}\left[\left(1-\bar{g}_{k}\left(T_{k}\right)\right) V_{k}\left(T_{k}\right)+C_{k}+\right. \\
& \left.L E V_{k+1}\right]-r_{k} \frac{\partial V_{k}\left(T_{k}\right)}{\partial T_{k}}<0
\end{aligned}
$$

Note that $\partial U / \partial T_{k}<0$, since it represents the second order condition for the maximization

of $L E V_{1}$, i.e., given the concavity assumption for $V_{k}\left(t_{k}\right), \frac{\partial V_{k}\left(T_{k}\right)}{\partial T_{k}}>0$ and $\frac{\partial^{2} V_{k}\left(T_{k}\right)}{\left(\partial T_{k}\right)^{2}}<0$. Thus, by examining the sign of $d T_{k} / d r_{k}$ we can determine the effect of this parameter on the harvest age of the forest stand. If $d T_{k} / d r_{k}<0$, the effect of a higher discount rate would lead to a shorter rotation age for the current crop. If $d T_{k} / d r_{k}>0$, the impact of this parameter would lead to a longer rotation age for the current crop.

\section{A.1. Impact of a higher current probability of fire risk level}


In this case, using a risk level variable $w_{k}$ :

$$
\begin{aligned}
& U=\frac{\partial V_{k}\left(T_{k}\right)}{\partial T_{k}}+w_{k} \lambda_{k}\left(T_{k}\right)\left[\bar{g}_{k}\left(T_{k}\right) V_{k}\left(T_{k}\right)-C_{k}\right]-\left(r_{k}+w_{k} \lambda_{k}\left(T_{k}\right)\right) V_{k}\left(T_{k}\right)- \\
& \left(r_{k}+w_{k} \lambda_{k}\left(T_{k}\right)\right) L E V_{k+1} \\
& \frac{\partial U}{\partial w_{k}}=-\lambda_{k}\left(T_{k}\right) V_{k}\left(T_{k}\right)\left(1-\bar{g}_{k}\left(T_{k}\right)\right)-\lambda_{k}\left(T_{k}\right) C_{k}-\lambda_{k}\left(T_{k}\right) L E V_{k+1}<0, \frac{d T_{k}}{d w_{k}}<0
\end{aligned}
$$

Thus, a higher overall fire risk level would result in a younger harvest age for the current crop.

\section{A.2. Impact of a higher future probability of fire risk level}

In this case, we need to analyze the impact of higher future parameters of the $n$th timber crop on the rotation age of the current stand, by focusing only on future land values $L E V_{k+1}-$ last term on the RHS in Eq. (15). Thus:

$$
\frac{d T_{k}}{d \mathrm{w}_{n}}=-\left(\frac{\partial U}{\partial \mathrm{w}_{n}} / \frac{\partial U}{\partial T_{k}}\right), \text { for } n>k
$$

Similarly to the situation of the current parameters, we need to identify the sign of $\frac{d T_{k}}{d \mathrm{w}_{n}}$ to determine the effect of future risk of fires on the harvest age for the current crop. The integral $\int_{0}^{T_{i}} \emptyset_{i} d x_{i}$ with $i=k+1$ of future land values $L E V_{k+1}$ depends on the future risk of fire. In order to differentiate the integral, we utilize the technique of differentiation under the integral sign, i.e., $\frac{\partial}{\partial x} \int f(x, w)=\int \frac{\partial}{\partial x} f(x, w)$. Thus: 


$$
\begin{aligned}
& \frac{\partial U}{\partial \mathrm{w}_{n}}= \\
& -\left(r_{k}+\lambda_{k}\left(T_{k}\right)\right)\left\{-\left(m_{n}\left(T_{n}\right)\right)\left[V_{n}\left(T_{n}\right)-C_{n}\right]-\right. \\
& \quad e^{\left(r_{n} T_{n+} \mathrm{w}_{n} m_{n}\left(T_{n}\right)\right)} \int_{0}^{T_{n}}\left(\lambda _ { n } ( T _ { n } ) ( \overline { g } _ { n } ( T _ { n } ) V _ { n } ( T _ { n } ) - C _ { n } ) \left(\mathrm{w}_{n} m_{n}\left(T_{n}\right)-\right.\right. \\
& \\
& \left.1) e^{-\left(r_{n} T_{n+} \mathrm{w}_{n} m_{n}\left(T_{n}\right)\right)} d T_{n}\right\} e^{-\sum_{j=k+1}^{n-1}\left(r_{j} T_{j}+m_{j}\left(T_{j}\right)\right)} e^{-\left(r_{n} T_{n+} \mathrm{w}_{n} m_{n}\left(T_{n}\right)\right)}-\left(r_{k}+\right. \\
& \left.\quad \lambda_{k}\left(T_{k}\right)\right)\left\{\sum _ { i = n + 1 } ^ { \infty } \left[V_{i}\left(T_{i}\right)-C_{i}+\right.\right. \\
& \left.\quad e^{\left(r_{i} T_{i}+m_{i}\left(T_{i}\right)\right)} \int_{0}^{T_{i}} \emptyset_{i} d X_{i}\right]\left(-m_{n}\left(T_{n}\right)\left[e^{-\left(r_{i-1} T_{i-1+} \mathrm{w}_{i-1} m_{i-1}\left(T_{i-1}\right)\right)} e^{-\left(r_{i} T_{i+} \mathrm{w}_{i} m_{i}\left(T_{i}\right)\right)}\right]\right\} \\
& >0, \quad \frac{d T_{k}}{d \mathrm{w}_{n}}>0
\end{aligned}
$$

A higher probability of fire risk for a future timber crop would lead to a longer rotation age for the current timber crop.

\section{A.3. Impact of a higher current salvageable portion level}

To quantify the effect of an increased salvageable portion level, we have :

$$
\begin{aligned}
& \frac{d T_{k}}{d \bar{g}_{k}}=-\left(\frac{\partial U}{\left.d \bar{g}_{k}\right)} / \frac{\partial U}{\partial T_{k}}\right) \\
& \frac{\partial U}{d \bar{g}_{k}}=\lambda_{k}\left(T_{k}\right) V_{k}\left(T_{k}\right)>0, \frac{d T_{k}}{d \bar{g}_{k}}>0
\end{aligned}
$$

Therefore, a higher salvageable portion level would lead to a longer rotation age for the current crop.

\section{A.4. Impact of a higher future salvageable portion level}

In this case, we have: 


$$
\begin{aligned}
& \frac{d T_{k}}{d \bar{g}_{n}}=-\left(\frac{\partial U}{\partial \bar{g}_{n}} / \frac{\partial U}{\partial T_{k}}\right) \\
& \quad \frac{\partial U}{\partial \bar{g}_{n}} \\
& \quad=-\left(r_{k}+\lambda_{k}\left(T_{k}\right)\right)\left\{\int_{n}^{T_{n}} \lambda_{n}\left(T_{n}\right) V_{n}\left(T_{n}\right) e^{-\left(r_{n} T_{n+} m_{n}\left(T_{n}\right)\right)} d T_{n} e^{-\left(\sum_{j=k+1}^{n-1}\left(r_{j} T_{j}+m_{j}\left(T_{j}\right)\right)\right.}\right\}
\end{aligned}
$$

Thus, an increased salvageable portion for a future timber crop would lead to a shorter rotation for the current timber crop.

\section{Appendix B. Derivation of the generalized Reed model (constant wildfire risk)}

Reed (1984) assumed that the catastrophic event followed a homogenous Poison process that occurs independently at the same average probability $\lambda$ per unit of time. The probability that a catastrophic event may affect a forest stand before reaching the economically optimal rotation age $T$ was $\operatorname{Pr}(x<T)=1-e^{-\lambda T}$ and the probability of the stand reaching the optimal rotation without being affected by a catastrophic event was $\operatorname{Pr}(x=T)=e^{-\lambda T}$. Thus, the net revenues for a forest landowner $Y_{n}$ for the first rotation would depend on two states of the world:

$$
Y_{n}=\left\{\begin{array}{cc}
\bar{g}\left(X_{n}\right) P Q\left(X_{n}\right)-C & \text { if } X_{n}<T \\
P Q(T)-C & \text { if } X_{n}=T
\end{array}\right.
$$

The $L E V$ takes the following form:

$$
\begin{aligned}
L E V(T)= & \frac{r+\lambda}{r\left(1-e^{-(r+\lambda) T}\right)}\left\{[P Q(T)-C] e^{-(r+\lambda) T}+\int_{0}^{T} \lambda\left[\bar{g}\left(X_{n}\right) P Q\left(X_{n}\right)-\right.\right. \\
& \left.C] e^{-(r+\lambda) X} d X\right\}
\end{aligned}
$$


Under the generalized Reed model (GRM), by defining $L E V_{i}$ as the land expectation value at the beginning of the $i$ th timber crop, the land expectation value at the beginning of the first timber crop $L E V_{1}$ is formulated as follows:

$$
\begin{aligned}
L E V_{1}= & -C_{0}+\left\{P_{1}\left(T_{1}\right) Q_{1}\left(T_{1}\right)-C_{1}+e^{\left(r_{1}+\lambda_{1}\right) T_{1}} \int_{0}^{T_{1}} \lambda_{1}\left[\bar{g}_{1}\left(X_{1}\right) P_{1}\left(X_{1}\right) Q_{1}\left(X_{1}\right)-\right.\right. \\
& \left.\left.C_{1}\right] e^{-\left(r_{1}+\lambda_{1}\right) X_{1}} d X_{1}\right\} e^{-\left(r_{1}+\lambda_{1}\right) T_{1}}+\left\{P_{2}\left(T_{2}\right) Q_{2}\left(T_{2}\right)-C_{2}+e^{\left(r_{2}+\lambda_{2}\right) T_{2}}\right. \\
& \left.\int_{0}^{T_{2}} \lambda_{2}\left[\bar{g}_{2}\left(X_{2}\right) P_{2}\left(X_{2}\right) Q_{2}\left(X_{2}\right)-C_{2}\right] e^{-\left(r_{2}+\lambda_{2}\right) X_{2}} d X_{2}\right\} e^{-\left(r_{1}+\lambda_{1}\right) T_{1}} e^{-\left(r_{2}+\lambda_{2}\right) T_{2}}+
\end{aligned}
$$

Eq. (B3) represents the sum of economic returns under the presence of catastrophic risk associated with an infinite number of successive timber crops. Rearranging eq. B3, we obtain:

$$
\begin{aligned}
L E V_{1}= & -C_{0}+\sum_{i=1}^{\infty}\left[P_{i}\left(T_{i}\right) Q\left(t_{i}\right)-C_{i}+e^{\left(r_{i}+\lambda_{i}\right) T_{i}} \int_{0}^{T_{i}} \lambda_{i}\left[\bar{g}_{i}\left(X_{i}\right) P_{i}\left(X_{i}\right) Q\left(X_{i}\right)-\right.\right. \\
& \left.\left.C_{i}\right] e^{-\left(r_{i}+\lambda_{i}\right) X_{i}} d X_{i}\right] e^{-\left(\sum_{j=1}^{i}\left(r_{j}+\lambda_{j}\right) T_{j}\right)}
\end{aligned}
$$

Defining $\emptyset_{i}=\lambda_{i}\left[\bar{g}_{i}\left(X_{i}\right) P_{i}\left(X_{i}\right) Q\left(X_{i}\right)-C_{i}\right] e^{-\left(r_{i}+\lambda_{i}\right) X_{i}}$, Eq. (B.4) can be expressed as:

$$
L E V_{1}=-C_{0}+\left[P_{1}\left(T_{1}\right) Q_{1}\left(T_{1}\right)+e^{\left(r_{1}+\lambda_{1}\right) T_{1}} \int_{0}^{T_{1}} \emptyset_{1} d X_{1}\right] e^{-\left(r_{1}+\lambda_{1}\right) T_{1}}+e^{-\left(r_{1}+\lambda_{1}\right) T_{1}} L E V_{2}
$$

To explore the optimal conditions for the optimal harvest age, Eq. (B.5) can be reformulated as

$$
\begin{gathered}
L E V_{1}=-C_{0}+\sum_{i=1}^{k-1}\left\{P_{i}\left(T_{i}\right) Q_{i}\left(T_{i}\right)-C_{i}+e^{\left(r_{i}+\lambda_{i}\right) T_{i}} \int_{0}^{T_{i}} \emptyset_{i} d X_{i}\right\} e^{-\left(\sum_{j=1}^{i}\left(r_{j}+\lambda_{j}\right) T_{j}\right)}+ \\
\left\{P_{k}\left(T_{k}\right) Q_{k}\left(T_{k}\right)-C_{k}+e^{\left(r_{k}+\lambda_{k}\right) T_{k}} \int_{0}^{T_{k}} \emptyset_{k} d X_{k}\right\}+ \\
\sum_{i=k+1}^{\infty}\left\{\left[P_{i}\left(T_{i}\right) Q\left(T_{i}\right)-C_{i}\right]+e^{\left(r_{i}+\lambda_{i}\right) T_{i}} \int_{0}^{T_{i}} \emptyset_{i} d X_{i}\right\} e^{-\left(\Sigma_{j=1}^{i}\left(r_{j}+\lambda_{j}\right) T_{j}\right)}
\end{gathered}
$$


Differentiating Eq. (B.6) with respect to $T_{k}$ :

$$
\begin{gathered}
\frac{\partial L E V_{1}}{\partial T_{k}}=\left\{\frac{\partial P_{k}\left(T_{k}\right)}{\partial T_{k}} Q_{k}\left(T_{k}\right)+P_{k}\left(T_{k}\right) \frac{\partial Q_{k}\left(T_{k}\right)}{\partial T_{k}}+\left(r_{k}+\lambda_{k}\right) e^{\left(r_{k}+\lambda_{k}\right) T_{k}} \int_{0}^{T_{k}} \emptyset_{k} d X_{k}+\right. \\
\left.e^{\left(r_{k}+\lambda_{k}\right) T_{k}} \emptyset_{k}\right\} e^{-\sum_{j=1}^{k}\left(r_{j}+\lambda_{j}\right) T_{j}}-\quad\left\{P_{k}\left(T_{k}\right) Q_{k}\left(T_{k}\right)-C_{k}+\right. \\
\left.e^{\left(r_{k}+\lambda_{k}\right) T_{k}} \int_{0}^{T_{k}} \emptyset_{k} d X_{k}\right\}\left(r_{k}+\lambda_{k}\right) e^{-\sum_{j=1}^{k}\left(r_{j}+\lambda_{j}\right) T_{j}}- \\
\sum_{i=k+1}^{\infty}\left\{\left[P_{i}\left(T_{i}\right) Q_{i}\left(T_{i}\right)-C_{i}\right]+e^{\left(r_{i}+\lambda_{i}\right) T_{i}} \int_{0}^{T_{i}} \emptyset_{i} d X_{i}\right\}\left(r_{k}+\lambda_{k}\right) e^{-\sum_{j=1}^{i}\left(r_{j}+\lambda_{j}\right) T_{j}} \\
=\mathrm{n}
\end{gathered}
$$

We obtain the following relationships:

$$
\begin{gathered}
\frac{\partial V_{k}\left(T_{k}\right)}{\partial T_{k}}+e^{\left(r_{k}+\lambda_{k}\right) T_{k}} \emptyset_{k}=\left(r_{k}+\lambda_{k}\right) V_{k}\left(T_{k}\right)+\left(r_{k}+\lambda_{k}\right) L E V_{k+1} \\
\varphi\left(T_{k}\right)=\frac{\frac{\partial V_{k}\left(T_{k}\right)}{\partial T_{k}}+e^{\left(r_{k}+\lambda_{k}\right) T_{k} \emptyset_{k}-\left(r_{k}+\lambda_{k}\right) V_{k}\left(T_{k}\right)}}{r_{k}+\lambda_{k}}
\end{gathered}
$$

\section{B.1. Comparative static conditions for the constant wildfire risk}

$$
\begin{aligned}
U= & \frac{\partial L E V_{1}}{\partial T_{k}}=\frac{\partial V_{k}\left(T_{k}\right)}{\partial T_{k}}+e^{\left(r_{k}+\lambda_{k}\right) T_{k}} \emptyset_{k}-\left(r_{k}+\lambda_{k}\right) V_{k}\left(T_{k}\right)-\left(r_{k}+\lambda_{k}\right) L E V_{k+1} \\
\frac{\partial U}{\partial T_{k}}= & \frac{\partial^{2} V_{k}\left(T_{k}\right)}{\left(\partial T_{k}\right)^{2}}-\lambda_{k}\left[\left(1-\bar{g}_{k}\left(T_{k}\right)\right) \frac{\partial V_{k}\left(T_{k}\right)}{\partial T_{k}}\right]-r_{k} \frac{\partial V_{k}\left(T_{k}\right)}{\partial T_{k}} \text { with } \partial U / \partial T_{k}<0 \\
& \frac{\partial V_{k}\left(T_{k}\right)}{\partial T_{k}}>0 \text { and } \frac{\partial^{2} V_{k}\left(T_{k}\right)}{\left(\partial T_{k}\right)^{2}}<0
\end{aligned}
$$

\section{B.2. Impact of a higher current probability of fire risk level}

$$
\frac{\partial U}{\partial \lambda_{k}}=-V_{k}\left(T_{k}\right)\left(1-\bar{g}_{k}\left(T_{k}\right)\right)-L E V_{k+1}-C_{k}<0, \frac{d T_{k}}{d \lambda_{k}}<0
$$

A higher probability of wildfire risk would result in a younger harvest age for the current crop. 
B.3. Impact of a higher future probability of fire risk level

$$
\begin{gathered}
\frac{\partial U}{\partial \lambda_{n}}=-\left(r_{k}+\lambda_{k}\right)\left\{\left(-T_{n}\right)\left[V_{n}\left(T_{n}\right)-C_{n}\right]-e^{\left(r_{n}+\lambda_{n}\right) T_{n}} \int_{0}^{T_{n}}\left(\bar{g}_{n}\left(T_{n}\right) V_{n}\left(T_{n}\right)-\right.\right. \\
\left.\left.C_{n}\right)\left(\lambda_{n} T_{n}-1\right) e^{-\left(r_{n}+\lambda_{n}\right) T_{n}} d T_{n}\right\} e^{-\left(\sum_{j=k+1}^{n}\left(r_{n}+\lambda_{n}\right) T_{n}\right)}-\quad\left(r_{k}+\right. \\
\left.\lambda_{k}\right)\left\{\sum_{i=n+1}^{\infty}\left[V_{i}\left(T_{i}\right)-C_{i}+e^{\left(r_{i}+\lambda_{i}\right) T_{i}} \int_{0}^{T_{i}} \emptyset_{i} d X_{i}\right]\left(-T_{n}\right) e^{-\left(\sum_{j=k+1}^{i}\left(r_{j}+\lambda_{j}\right) T_{j}\right)}\right\} \\
>0, \quad \frac{d T_{k}}{d \lambda_{n}}>0
\end{gathered}
$$

A higher probability of wildfire risk for a future timber crop would lead to a longer rotation age for the current timber crop.

\section{B.4. Effect of a higher current salvageable portion level}

$$
\frac{\partial U}{d \bar{g}_{k}}=\lambda_{k} V_{k}\left(T_{k}\right)>0, \frac{d T_{k}}{d \bar{g}_{k}}>0
$$

A higher salvageable portion level would lead to a longer rotation age for the current crop.

\section{B.5. Effect of a higher future salvageable portion level}

$$
\frac{\partial U}{\partial \bar{g}_{n}}=-\left(r_{k}+\lambda_{k}\right)\left\{\int_{0}^{T_{n}} \lambda_{n} V_{n}\left(T_{n}\right) e^{-\left(r_{n}+\lambda_{n}\right) T_{n}} d T_{n} e^{-\left(\sum_{j=k+1}^{n-1}\left(r_{n}+\lambda_{n}\right) T_{n}\right)}\right\}<0, \frac{d T_{k}}{d \bar{g}_{n}}<0
$$

An increased salvageable portion for a future timber crop would lead to a shorter rotation for the current timber crop. 


\section{References}

Amacher, G.S., Malik, A.S., Haight, R.G., 2005. Not getting burned: the importance of fire prevention in forest management. Land. Econ. 81, 284-302. doi:10.1016/j.forpol.2005.03.004

Amacher, G.S., Ollikainen, M., Koskela, E., 2009. Economics of Forest Resources. MIT Press, London, England. doi:10.1093/erae/jbq028

Barnett, J., Sheffield, R., 2004. Slash pine: characteristics, history, status, and trends, in: Dickens, E.D., Barnet, J.P., Hubbard, W.G., Jokela, E.L. (Eds.), Slash Pine: Still Growing and Growing! General Technical Report GTR SRS-76, U.S. Department of Agriculture. Asheville, NC, pp. 1-6.

Bedel, A., Mote, T., Goodrick, S.L., 2013. Climate change and associated fire potential for the southeastern united states in the 21. Int. J. Wildl. Fire 22, 1034-1043.

Butry, D., Mercer, E., Prestemon, J., Pye, J., Holmes, T., 2000. What is the price of catastrophic wildfire? J. For. 99, 9-7.

Chang, S.J., 1998. A generalized Faustmann model for the determination of optimal harvest age 652-659. Can. J. Forest. Res. 28, 652-659.doi: 10.1139/x98-017

Dooley, E., Barlow, R., 2013. 2012 cost and cost trends for forestry practices in the South. For. Landowner Oct, 22-29.

Englin, J., Boxall, P., Hauer, G., 2000. An empirical examination of optimal rotations in a multipleuse forest in the presence of fire risk. J. Agric. Resour. Econ. 25, 14-27.

Evans, J., 2009. The History of Tree Planting and Planted Forest, Planted forests: Uses, Impacts and Sustainability. FAO and CAB International, Rome, Italy.

Faustmann, M., 1995. Calculation of the value which forest land and immature stands possess for forestry. J. For. Econ. 1, 7-45.

Gjolberg, O., Guttormsen, A.G., 2002. Real options in the forest: What if prices are meanreverting? For. Policy Econ. 4, 13-20. doi:10.1016/S1389-9341(01)00076-4

Gong, P., Löfgren, K.G., 2008. Impacts of risk aversion on the optimal rotation with stochastic price. Nat. Resour. Model. 21, 385-415. doi:10.1016/j.jfe.2007.06.001

Insley, M., Rollins, K., 2005. On solving the multirotational timber harvesting problem with stochastic prices: a linear complementarity formulation. Am. J. Agric. Econ. 87, 735-755. 
Karl, T.R., Melillo, J.M., Peterson, T.C., 2009. Global Climate Change Impacts in the United States. Cambridge University Press, New York.

Li, C., Ter-Mikaelian, M., Perera, A., 1997. Temporal fire disturbance patterns on a forest landscape. Ecol. Modell. 99, 137-150. doi:10.1016/S0304-3800(96)01944-8

Lindenmayer, D.B., Noss, R.F., 2006. Salvage logging, ecosystem processes, and biodiversity conservation. Conserv. Biol. 20, 949-958. doi:10.1111/j.1523-1739.2006.00497.x

Liu, Y., Prestemon, J.P., Goodrick, S.L., Holmes, T.P., Stanturf, J. a, Vose, J.M., 2014. Future wildfire trends, impacts, and mitigation options in the Southern United States, in: Vose, J.M., Klepzing, K., Kier, D. (Eds.), Climate Change Adaptation and Mitigation Management Options: A Guide for Natural Resource Managers in Southern Forest Ecosystems. CRC Press, Boca Raton, pp. 85-125.

Mitchell, R.J., Liu, Y., O’Brien, J.J., Elliott, K.J., Starr, G., Miniat, C.F., Hiers, J.K., 2014. Future climate and fire interactions in the southeastern region of the United States. For. Ecol. Manage. 327, 316-326. doi:10.1016/j.foreco.2013.12.003

Myers, R.K., Van Lear, D.H., 1998. Hurricane-fire interactions in coastal forests of the south: A review and hypothesis. For. Ecol. Manage. 103, 265-276. doi:10.1016/S03781127(97)00223-5

Natural Interagency Coordination Center, 2014. Wildland fire summary and statistics annual report 2014. Available online at ttp://www.predictiveservices.nifc.gov/intelligence/ 2014_ Statssumm/2014Stats\&Summ.html

Oucalt, K., Wade, D., 2004. Fuels management reduces tree mortality from wildfires in southeastern United States. J. Appl. For. 28. 28-34.

Peterson, D.L., Wolken, J.M., Hollingsworth, T.N., Giardina, C.P., Littell, J.S., Joyce, L.A., Swanston, C.W., Handler, S.D., Rustad, L.E., Mcnulty, S.G., 2014. Regional highlights of climate change, in: Peterson, D.L., Vose, J.M., Patel-Weynand, T. (Eds.), Climate Change and United States Forests. Springer Science+ Business Media, New York, pp. 113-148.

Pienaar, L.V., Shiver, B.D., Rheney, J.W., 1996. Yield prediction for mechanically site- prepared slash pine plantations in the southeastern Coastal Plain. Technical Report 1996-3, University of Goergia PMRC, Athens, GA, 57 p.

Prestemon, J.P., Holmes, T., 2008. Timber Salvage Economics, in: Holmes, T.P., Prestemon, J.P., Abt, K. (Eds.), The Economics of Forest Disturbances: Wildfires, Storms and Invasive Species. Springer, Netherlands, pp. 167-190.

Reed, W., 1984. The effects of the risk of fire on the optimal rotation of a forest. J. Environ. Econ. Manage. 11, 180-190. doi:10.1016/0095-0696(84)90016-0 
Reed, W., Errico, D., 1985. Assessing the long-run yield of a forest stand subject to the risk of fire. Can. J. For. Res. 15, 680-687.doi: 10.1139/x85-111.

Saarinen, V.M., 2006. The effects of slash and stump removal on productivity and quality of forest regeneration operations - Preliminary results. Biomass Bioenergy 30, 349-356. doi:10.1016/j.biombioe.2005.07.014

Stainback, G.A., Alavalapati, J.R.R., 2002. Economic analysis of slash pine forest carbon sequestration in the southern US. J. For. Econ. 117, 105-117.

Stainback, G.A., Alavalapati, J.R.R., 2004. Modeling catastrophic risk in economic analysis of forest carbon sequestration. Nat. Resour. Model. 17, 299-317.

Stanturf, J.A., Goodrick, S.L., 2013. Fire, in: Wear, D., Greis, J. (Eds.), The Southern Forest Futures Project: Technical Report. U.S. Depoartment of Agriculture Forest Service, General Technical Report SRS-178. Asheville, NC, p. 509-542.

Stein, S., Menakis, J., Carr, M., Comas, S., Stewart, S., Cleveland, H., Bramwell, L., Radeloff, V., 2013. Wildfire, wildlands, and people: understanding and preparing for wildfire in the wildland-urban interface. General Technical Report RMRS-GTR-299, U.S. Department of Agriculture Forest Service. Fort Collins, CO, 36 p.

Susaeta, A., Alavalapati, J.R.R., Carter, D.R., 2009. Modeling impacts of bioenergy markets on nonindustrial provate forest management in the southeastern United States. Nat. Resour. Model. 22, 345-369.

Talbert, C., Marshall, D., 2005. Plantation productivity in the Douglas-fir region under intensive silvicultural practices: results from research and operations. J. For. 103, 65-70.

Timber Mart-South, 2014. Timber mart-south market news quarterly, 4th quarter 2014. University of Georgia, Athens, GA.

Timber Mart South. 2015. Timber mart south market newsletter: quarterly stumpage prices 1981-2014. Athens, GA.

Yousefpour, R., Bredahl Jacobsen, J., Thorsen, B.J., Meilby, H., Hanewinkel, M., Oehler, K., 2012. A review of decision-making approaches to handle uncertainty and risk in adaptive forest management under climate change. Ann. For. Sci. 69, 1-15. doi:10.1007/s13595-0110153-4 


\section{Figures captions}

Fig.1. The optimal harvest age under different levels of wildfire risk $t_{o}$ and salvageable portion $g=0.5$

Fig.2. The optimal harvest age under different levels of salvageable portion $g$ and wildfire risk $t_{o}=1$ 
Fig. 1. The optimal harvest age and levels of wildfires

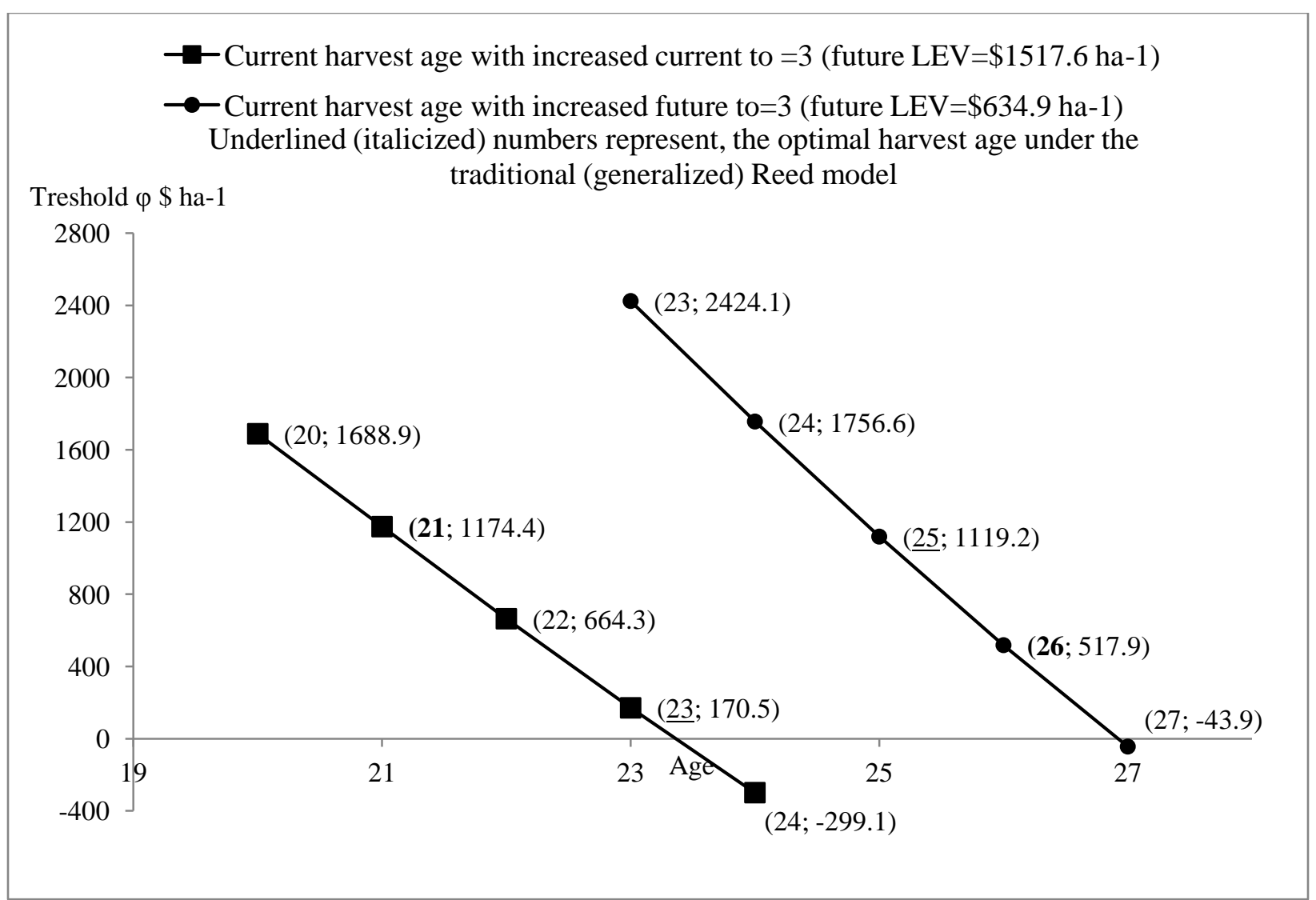




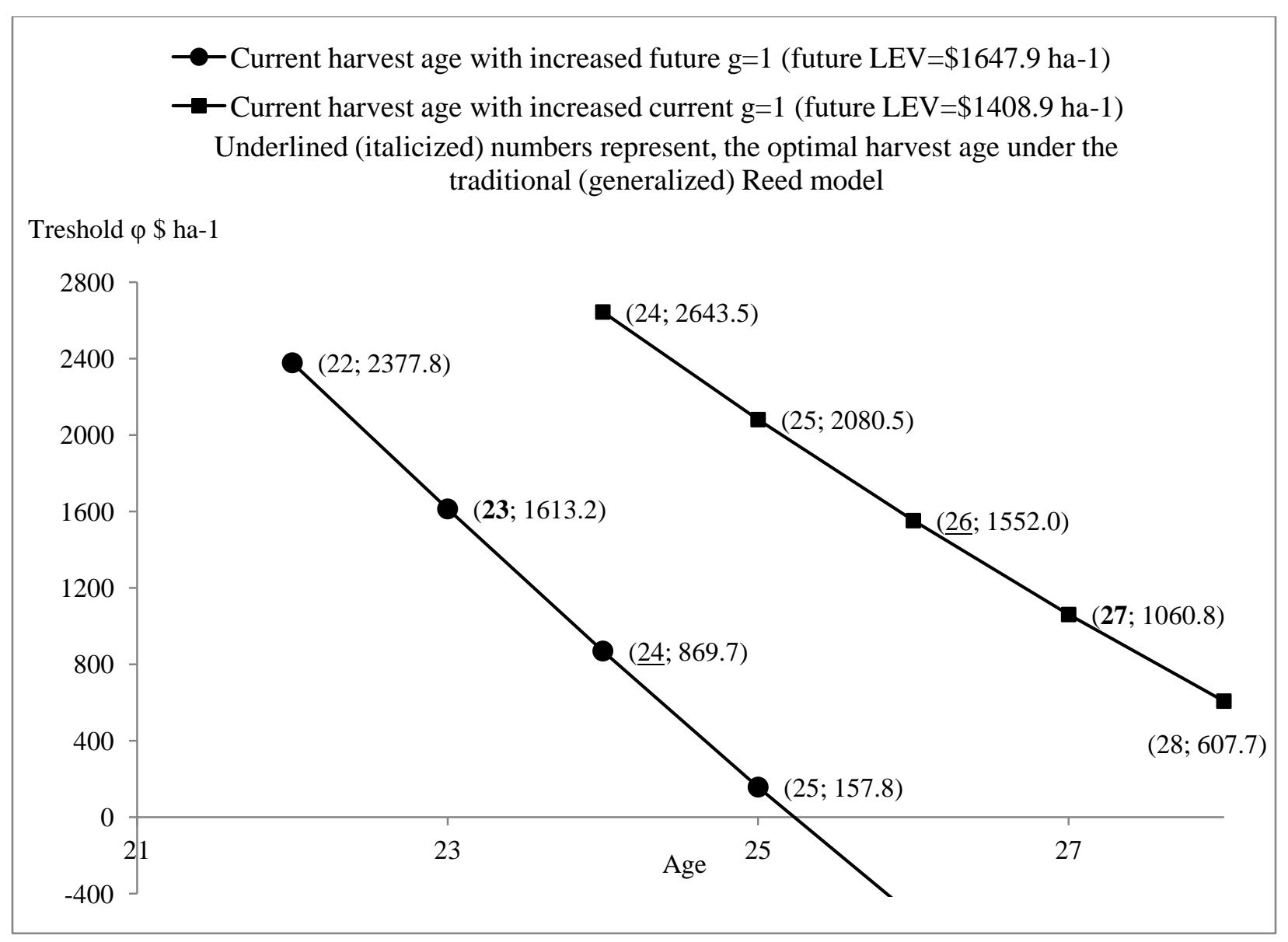




\section{Table 1}

Definition of Parameters of the GRM.

\begin{tabular}{cl}
\hline Parameters & Definition \\
\hline$P_{i}\left(T_{i}\right)$ & Price of stumpage of $T_{i}$ year old trees at the ith timber crop \\
$Q_{i}\left(T_{i}\right)$ & Volume of a stand of $T_{i}$ year old stand from the ith timber crop \\
$C_{i}$ & Reforestation cost for the ith timber crop \\
$r_{i}$ & Discount rate associated with the ith timber crop \\
$\lambda_{i}\left(T_{i}\right)$ & Probability of fire risk or fire arrival rate at time $T_{i}$ associated with the \\
& ith timber crop \\
$\mathrm{m}_{i}\left(T_{i}\right)$ & Sum of the probability of fire arrival at time $T_{i}$ associated with the ith \\
& timber crop \\
$\bar{g}_{i}$ & Mean salvageable portion of associated with ith timber crop if the \\
& catastrophic event arrives at time $X_{i}<T_{i}$ \\
$\mathrm{C}_{0}$ & Regeneration cost at the beginning of the first timber crop \\
&
\end{tabular}




\section{Table 2}

Land expectation value ( $L E V)$, threshold values $\varphi$ and optimal harvest ages under different wildfire risks (a) and salvageable portions (b).

\begin{tabular}{|c|c|c|c|c|c|}
\hline \multicolumn{6}{|c|}{ Wildfire risk case (a) } \\
\hline \multicolumn{6}{|c|}{$g=0.5$} \\
\hline \multicolumn{3}{|c|}{$t_{o}=1$} & \multicolumn{3}{|c|}{$t_{o}=3$} \\
\hline $\operatorname{LEV}(T)$ & $\varphi(T)$ & Age & $\operatorname{LEV}(T)$ & $\varphi(T)$ & Age \\
\hline \multicolumn{2}{|c|}{$\mathrm{US} \$ \mathrm{ha}^{-1}$} & year & \multicolumn{2}{|c|}{$\mathrm{US} \$ \mathrm{ha}^{-1}$} & year \\
\hline 1494.3 & 2424.1 & 23 & 576.6 & 1688.9 & 20 \\
\hline 1514.0 & 1756.6 & 24 & 611.6 & 1174.4 & 21 \\
\hline 1517.6 & 1119.2 & 25 & 630.2 & 664.3 & 22 \\
\hline 1507.8 & 517.9 & 26 & 634.9 & 170.5 & 23 \\
\hline 1487.0 & -43.9 & 27 & 628.1 & -299.1 & 24 \\
\hline
\end{tabular}

Salvageable portion case (b)

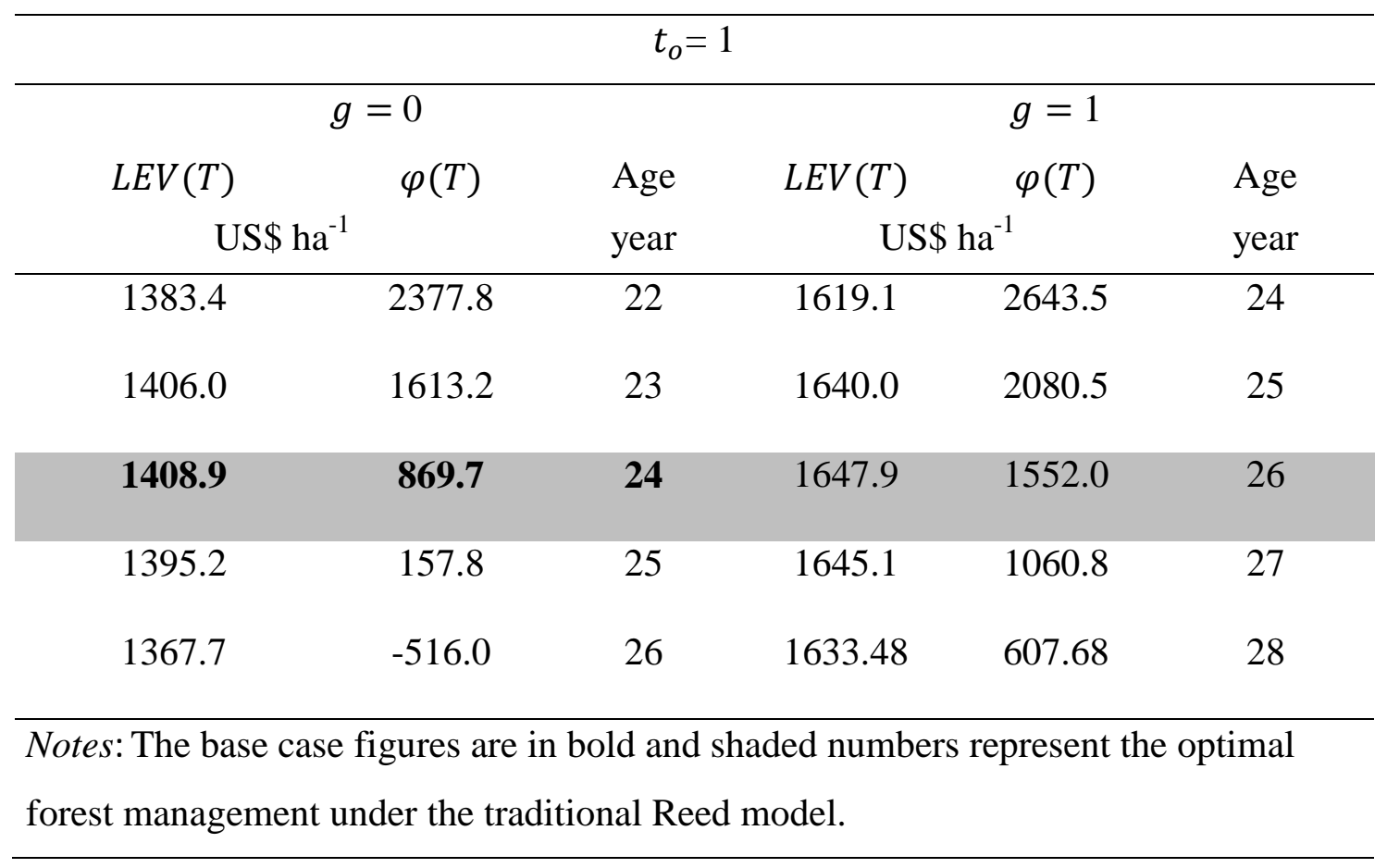




\section{Table 3}

The optimal harvest age for different levels of constant and rising risk of wildfire and salvageable portion $g=0.5$.

\begin{tabular}{|c|c|c|c|c|c|}
\hline \multicolumn{6}{|c|}{ Constant risk (a) } \\
\hline \multicolumn{3}{|c|}{$t_{o}=1$} & \multicolumn{3}{|c|}{$t_{o}=2$} \\
\hline $\operatorname{LEV}(T)$ & $\varphi(T)$ & age & $\operatorname{LEV}(T)$ & $\varphi(T)$ & age \\
\hline \multicolumn{2}{|c|}{ US $\$ \mathrm{ha}^{-1}$} & year & \multicolumn{2}{|c|}{ US $\$ \mathrm{ha}^{-1}$} & year \\
\hline 1560.7 & 1681.6 & 24 & -173.4 & 2539.9 & 19 \\
\hline 1570.7 & 1119.2 & 25 & -42.6 & 2147.5 & 20 \\
\hline 1562.2 & 577.2 & 26 & 51.8 & 1718.5 & 21 \\
\hline 1538.6 & $\underline{60.3}$ & 27 & 114.9 & 1269.4 & 22 \\
\hline 1502.9 & -429.4 & 28 & 151.7 & 814.15 & 23 \\
\hline 1457.9 & -890.8 & 29 & 167.0 & 363.1 & 24 \\
\hline 1405.4 & -1324.0 & 30 & 164.8 & -75.9 & 25 \\
\hline \multicolumn{6}{|c|}{ Rising risk (b) } \\
\hline \multicolumn{3}{|c|}{$t_{o}=1.9$} & \multicolumn{3}{|c|}{$t_{o}=4$} \\
\hline $\operatorname{LEV}(T)$ & $\varphi(T)$ & age & $\operatorname{LEV}(T)$ & $\varphi(T)$ & age \\
\hline \multicolumn{2}{|c|}{ US\$ ha ${ }^{-1}$} & year & \multicolumn{2}{|c|}{ US\$ ha ${ }^{-1}$} & year \\
\hline 1004.9 & 1094.0 & 23 & 334.4 & $\underline{1465.2}$ & $\underline{19}$ \\
\hline 1010.0 & 537.6 & 24 & 371.2 & 1006.0 & 20 \\
\hline 1002.8 & $\underline{11.9}$ & $\underline{25}$ & 391.8 & 541.3 & 21 \\
\hline 985.5 & -479.3 & 26 & 398.6 & 84.2 & 22 \\
\hline 960.3 & -934.8 & 27 & 394.0 & -355.9 & 23 \\
\hline
\end{tabular}

Notes: Italicized numbers with single underlining represent, respectively, the effect of increased future constant $\left(t_{o}=2\right)$ and rising $\left(t_{o}=4\right)$ risk on the current optimal harvest age. Regular numbers with single underlining represent the effect of increased current constant $\left(t_{o}=2\right)$ and rising $\left(t_{o}=4\right)$ risk on the current optimal harvest age. The base case figures are in bold and shaded numbers represent the optimal forest management under the traditional Reed model. 